\title{
Focal brain trauma in the cryogenic lesion model in mice
}

\author{
Furat Raslan ${ }^{*}$, Christiane Albert-Weißenberger ${ }^{2}$, Ralf-Ingo Ernestus ${ }^{1}$, Christoph Kleinschnitz $^{2}$ and \\ Anna-Leena Sirén ${ }^{1}$
}

\begin{abstract}
The method to induce unilateral cryogenic lesions was first described in 1958 by Klatzo. We describe here an adaptation of this model that allows reliable measurement of lesion volume and vasogenic edema by 2, 3, 5triphenyltetrazolium chloride-staining and Evans blue extravasation in mice. A copper or aluminium cylinder with a tip diameter of $2.5 \mathrm{~mm}$ is cooled with liquid nitrogen and placed on the exposed skull bone over the parietal cortex (coordinates from bregma: $1.5 \mathrm{~mm}$ posterior, $1.5 \mathrm{~mm}$ lateral). The tip diameter and the contact time between the tip and the parietal skull determine the extent of cryolesion. Due to an early damage of the blood brain barrier, the cryogenic cortical injury is characterized by vasogenic edema, marked brain swelling, and inflammation. The lesion grows during the first 24 hours, a process involving complex interactions between endothelial cells, immune cells, cerebral blood flow, and the intracranial pressure. These contribute substantially to the damage from the initial injury. The major advantage of the cryogenic lesion model is the circumscribed and highly reproducible lesion size and location.
\end{abstract}

Keywords: Experimental brain trauma, Cryolesion, Secondary traumatic brain damage, Mice

\section{Introduction}

Traumatic brain injury (TBI) and its sequel represent a major cause of disability and death worldwide [1]. TBI consists of the primary irreversible damage and a multitude of secondary cascades, resulting progressively in tissue degeneration and neurological impairment [2-4]. The outcome of severe cerebral lesion does not solely depend on the primary damage, but on the extent of secondary lesions.

Several models of experimental traumatic brain injury have been developed in an attempt to reproduce different aspects of the biomechanical impairments and neurological deficits observed in human head injury. The fluid percussion model produces brain injury by rapid injection of fluid into the closed cranial cavity $[5,6]$. The controlled cortical impact trauma is induced by using a pneumatic impactor to impact exposed brain with a measurable, controllable impact speed and cortical deformation [7]. In comparison to these two models of

\footnotetext{
* Correspondence: Raslan.F@nch.uni-wuerzburg.de

${ }^{1}$ Department of Neurosurgery, University of Würzburg, 97080 Würzburg

Germany

Full list of author information is available at the end of the article
}

focal TBI, the unilateral cryogenic lesion model first described in 1958 by Klatzo [8] induces lesions that are well circumscribed and highly reproducible in size and location. Due to an early damage of the blood brain barrier (BBB), the cryogenic cortical injury leads to vasogenic edema, marked brain swelling, and inflammation. The histological and pathological features of cryogenic lesions share many of the hallmark characteristics of human TBI $[9,10]$. For example, upregulation of inflammatory cytokine expression is detected by real-time PCR as early as $24 \mathrm{~h}$ after cryogenic lesion [11]. The cryogenic lesion model can further be used to study long term neurodegenerative changes similar to late complications of human head injury such as global brain atrophy, cognitive impairment, and behavioural abnormalities $[12,13]$. Furthermore, cryogenic cortical injury has been shown to lead to late brain atrophy and impairment of spatial memory, two key readout parameters for late consequences of TBI [12]. Yet another advantage of the cryogenic model is its technical simplicity as craniotomy is not required.

\section{Biomed Central}

(c) 2012 Raslan et al; licensee BioMed Central Ltd. This is an Open Access article distributed under the terms of the Creative Commons Attribution License (http://creativecommons.org/licenses/by/2.0), which permits unrestricted use, distribution, and reproduction in any medium, provided the original work is properly cited. 


\section{Material}

\section{Experimental equipment}

1. Ketanest-S $25 \mathrm{mg} / \mathrm{ml}$ (S-ketamine hydrochloride) and Rompun 2\% (xylazine)

2. Stereotaxic device (TSE Systems GmbH, Bad Homburg) depicted in Figure 1

3. Liquid nitrogen, Cotton-tipped applicators, 3-0 Silk sutures

4. Cone-shaped copper or aluminium cylinder with tip diameter of $2.5 \mathrm{~mm}$ and a body coated with polystyrene (Figure 2)

5. Heating device

Setup of surgery and 2, 3, 5-triphenyltetrazolium chloride -staining

1. Scalpel (optional)

2. Scissors (e.g., delicate curved sharp/blunt iris scissors, Fine Science Tools Inc., Foster City, CA)

3. Forceps: One pair of splinter forceps (e.g., $90 \mathrm{~mm}$ curved splinter forceps, Aesculap AG, Tuttlingen, Germany)

4. Needle holder (e.g., Halsey Micro Needle Holder, Fine Science Tools)

5. Mouse brain matrix (e.g., mouse brain slicer matrix with $1 \mathrm{~mm}$ coronal slice intervals, Harvard Apparatus, Holliston, MA, USA)

6. Razor blade (e.g., SIH1 razor blades, Hartenstein Laborbedarf, Würzburg, Germany)

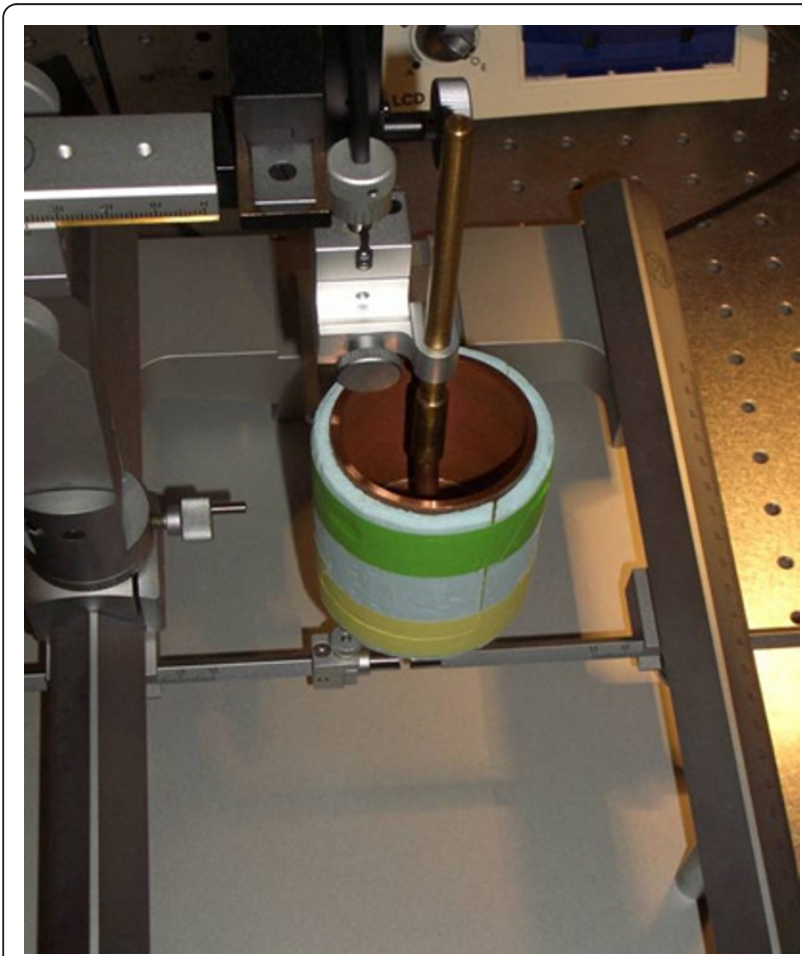

Figure 1 Stereotaxic device.

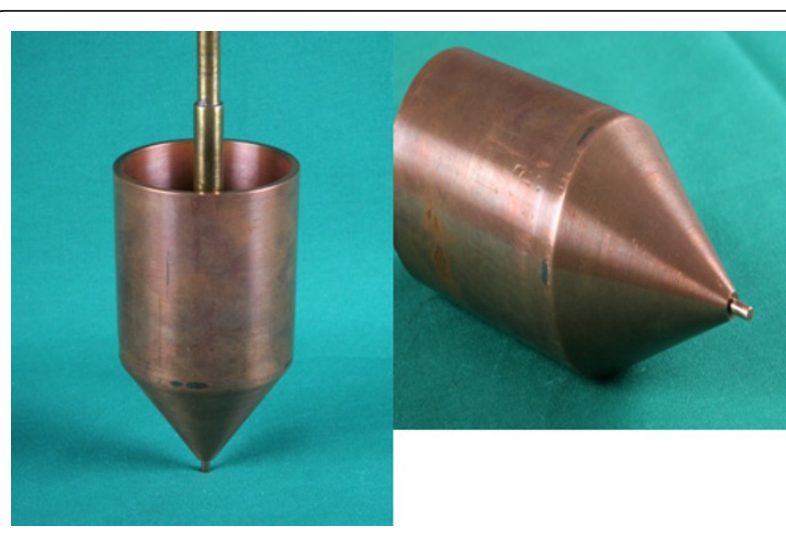

Figure 2 Cone-shaped copper cylinder with tip diameter of 2.5 $\mathrm{mm}$.

7. Phosphate-buffered saline (PBS)

8. 2, 3, 5-triphenyltetrazolium chloride (TTC) (e.g., Sigma-Aldrich, St. Louis, MO)

9. $2 \%$ Evans blue (Sigma)

9. ImageJ software (National Institutes of Health, USA) for planimetric calculation of lesion volumes

10. $4 \%$ paraformaldehyde, $\mathrm{NaCl}$

\section{Methods}

All animal experiments have to be conducted in accordance with the laws and regulations of the regulatory authorities for animal care, and they require an appropriate animal experimentation facility. Due to substantial strain and gender variations in mice, those crucial parameters are not interchangeable. In our laboratory, we use male, pathogen-free C57BL/6 mice (8-11 weeks) and genetically manipulated mice on a C57BL/6 background.

\section{Surgery}

1. Anaesthesia with an intraperitoneal injection of Ketanest-S $25 \mathrm{mg} / \mathrm{ml}$ and Rompun $2 \%$ in a dose of 0.1 $\mathrm{mg} / \mathrm{g}$ ketamine and $0.005 \mathrm{mg} / \mathrm{g}$ xylazine. The depth of surgical anaesthesia is verified before starting surgery.

2. 3-point rigid cranial fixation in stereotaxic device as depicted in Figure 3.

3. A midline sagittal scalp incision is made in the midline of the head (Figure 3).

4. The target area for lesion is on the right parietal skull, coordinates from bregma: $1.5 \mathrm{~mm}$ posterior, 1.5 $\mathrm{mm}$ lateral (Figure 4).

5. A cone-shaped copper or aluminium cylinder with a tip diameter of 1.5 or $2.5 \mathrm{~mm}$ will be filled with liquid nitrogen $\left(-196^{\circ} \mathrm{C}\right)$ and placed stereotactically on the right parietal skull (coordinates as described) for definite time $(60,90$, or 120 secs) (Figure 5). An extended contact time and more tip diameter range will increase the lesion volume. Sham-operated animals go through the 


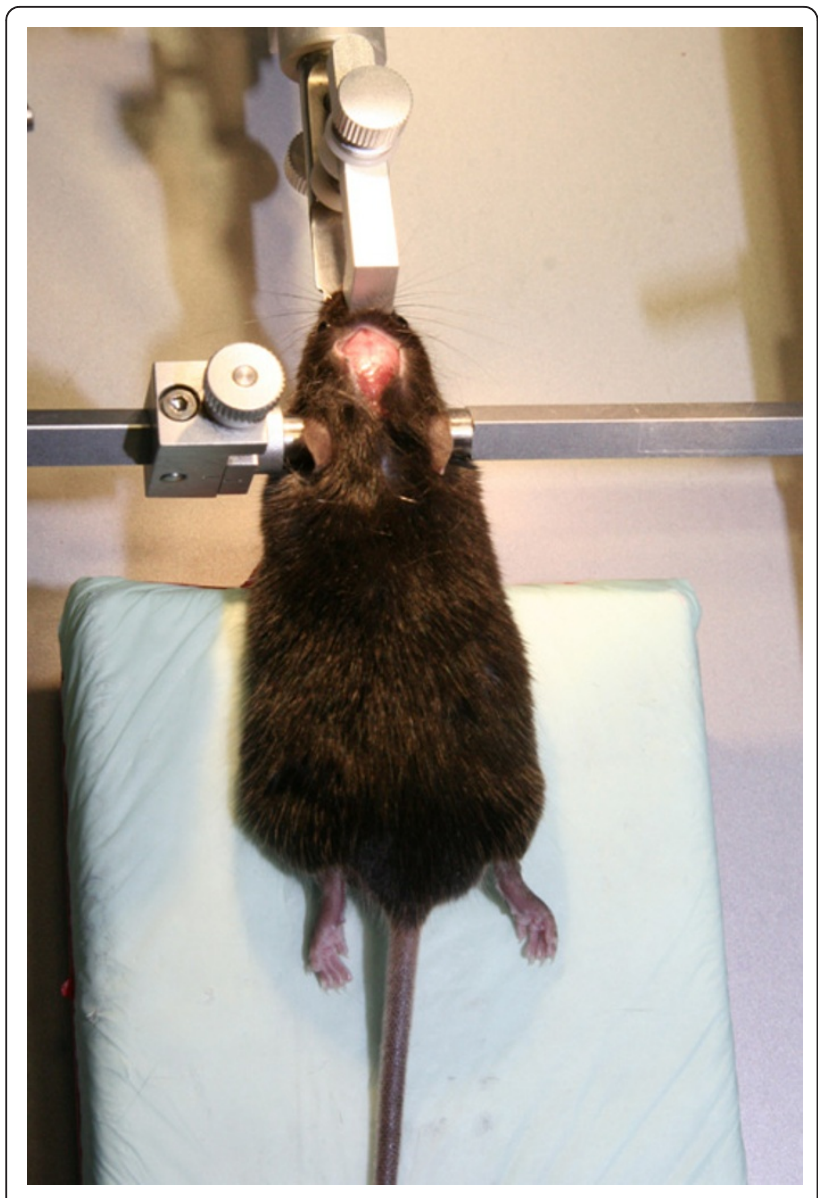

Figure 3 3-point rigid cranial fixation in stereotaxic device. A midline sagittal scalp incision is made to expose the skull bone.

same procedure without cooling the cylinder with liquid nitrogen.

6. The cone-shaped copper or aluminium cylinder is removed.

7. Wound closure by standard skin suture using a needle holder and, e.g., 3-0 Ethilon suture material (Figure 6).

The time required for surgery is usually $5-10 \mathrm{~min}$.

\section{Outcome}

Key readout parameters include the assessment of lesion size and the magnitude of blood brain barrier breakdown.

\section{Determination of lesion size}

The cortical lesions increase over the first $24 \mathrm{~h}$ because the penumbral area surrounding the cryogenic cortical lesion is subsequently involved in the definite lesion area. $24 \mathrm{~h}$ after cryogenic cortical lesion induction, the brains are removed and sliced up into $2-\mathrm{mm}$ thick sections according to the coronal plane using a mouse brain slice matrix (Harvard Apparatus,

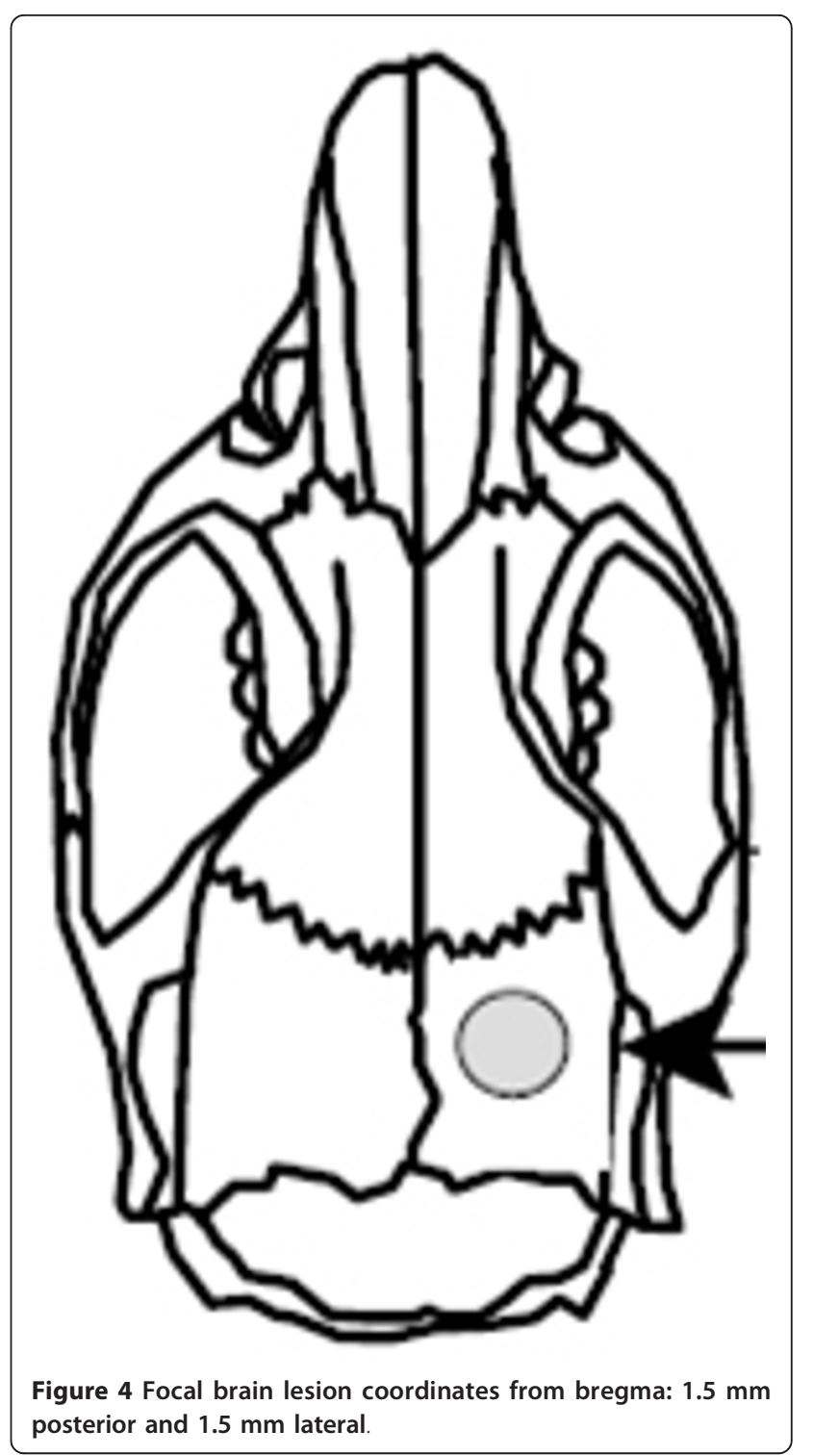

Holliston, MA, USA). The slices are immersed in $2 \%$ TTC in PBS to visualize the lesion size (Figure 7). According to the calculated lesion areas with the known slice thickness lesion volumes can be measured planimetrically [11].

Determination of blood brain barrier permeability

Commonly occurring vasogenic edema formation, as sequel of breakdown of the BBB after traumatic brain injury, is one of the most important intracranial causes for secondary brain damage, leading to an increased intracranial pressure, causing brain shift, and at last brain herniation [14].

Further important read out criteria within this animal model is the assessment of the cerebral vasculature permeability after breakdown of the BBB to evaluate the traumatic vasogenic edema formation. This procedure 


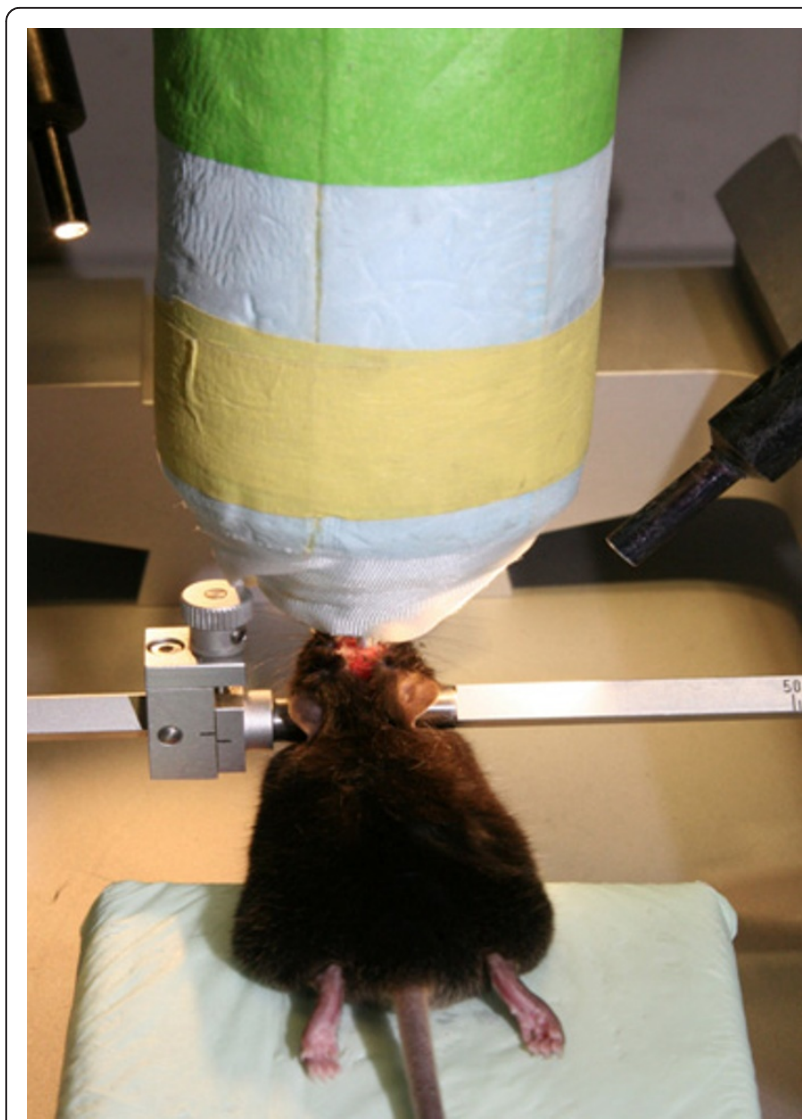

Figure 5 Cone-shaped aluminium cylinder (tip diameter 2.5 $\mathrm{mm})$ is filled with liquid nitrogen $\left(-196^{\circ} \mathrm{C}\right)$ and placed on the right parietal skull coordinates as described in figure 4).

can be easily and reliable investigated in the cryogenic cortical lesion model. 2\% Evan's Blue tracer diluted in $0.9 \% \mathrm{NaCl}$ is intravenously injected $2 \mathrm{~h}$ and $24 \mathrm{~h}$ after the induction of the cryogenic brain lesion. After $24 \mathrm{~h}$ the mice are killed with an overdose of the anesthetic

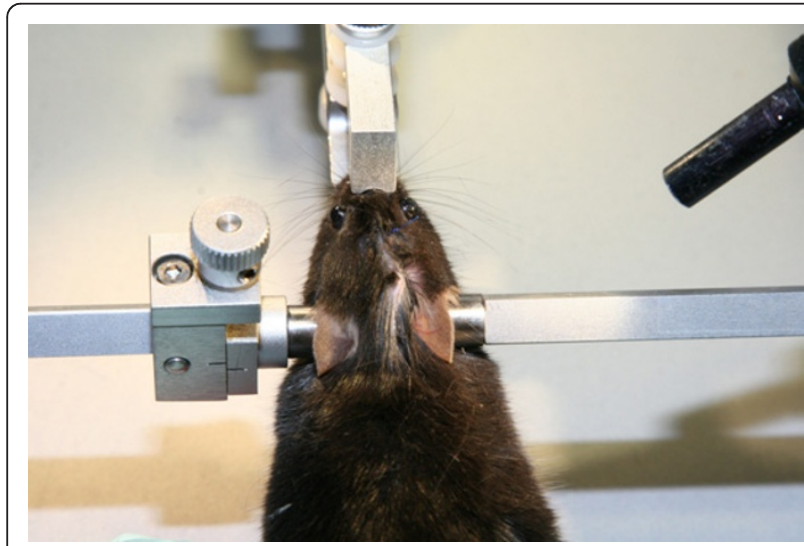

Figure 6 Standard skin suture using, e.g., a needle holder and 3,0 Ethilon suture material

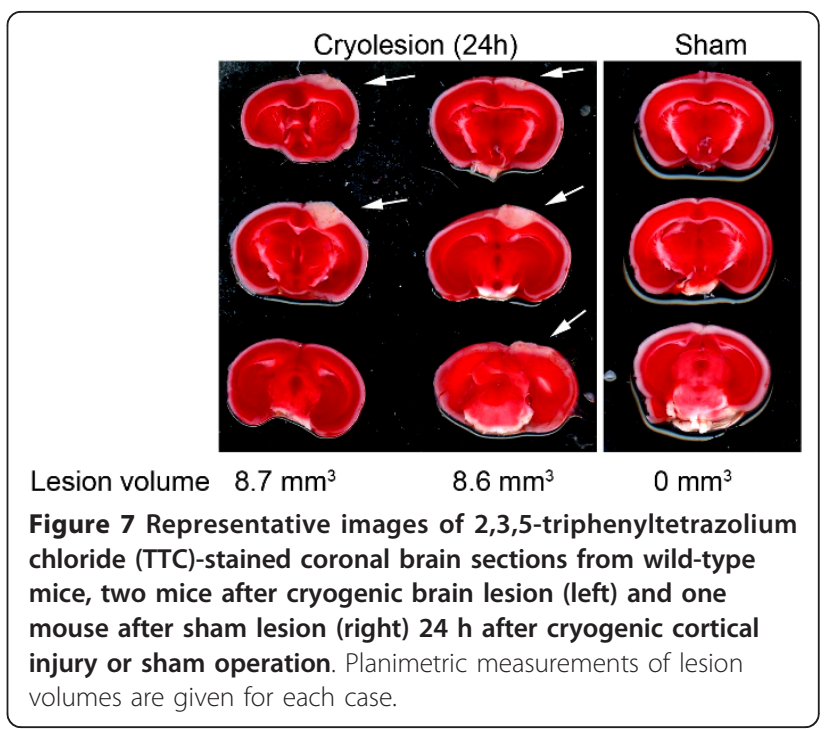

and were transcardially perfused with $4 \%$ paraformaldehyde, the brains are removed and sliced up into 2-mmthick sections according to the coronal plane using a mouse brain slice matrix. Planimetric measurements of the brain parenchyma stained with Evan's Blue (Figure 8) are used to calculate edema volumes [15]. According to the calculated lesion areas with the known slice thickness lesion volumes can be measured planimetrically $[11,16]$.

The pearls and pitfalls of the cryogenic lesion models are listed below.

\section{Advantages:}

- highly standardized lesion size and location

- lesion volume on TTC is a reliable readout
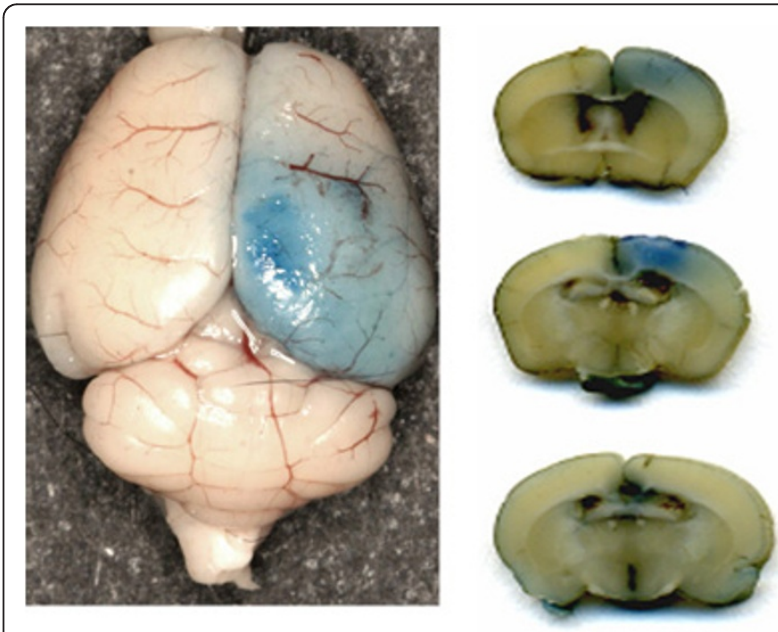

Figure 8 Evan's Blue staining to assess the magnitude of the breakdown of the blood brain barrier after cryogenic injury. 
- pronounced vasogenic edema and breakdown of the blood brain barrier that can easily be quantified by Evans blue extravasation

- technical simplicity, does not require craniotomy

- easily adaptable for mice

Disadvantages:

- not a mechanical trauma

- no counter coup, diffuse axonal injury or postcontusional bleeding

\section{Summary}

Unilateral cryogenic brain lesion in mice with subsequent focal brain lesion and breakdown of the BBB is a valid model to investigate the histological and pathological characteristics of brain trauma and develop novel therapeutic strategies to reduce neuronal cell death and vasogenic brain edema [11]. Clinically relevant readouts that can be used for testing of new therapies in this model include lesion size, vasogenic edema, and inflammation.

\section{Acknowledgements}

The authors wish to thank Mrs. Brigitte May for making the illustrating photographs. This publication was funded by the German Research Foundation (DFG) and the University of Wuerzburg in the funding programme Open Access Publishing

\section{Author details}

${ }^{1}$ Department of Neurosurgery, University of Würzburg, 97080 Würzburg, Germany. ${ }^{2}$ Department of Neurology, University of Würzburg, 97080 Würzburg, Germany.

\section{Authors' contributions}

FR carried out the cryolesion experiments, performed data analysis, and drafted the manuscript. CK participated in the design and coordination of the study and supervised the experiments. RIE participated in the design of the study and edited the manuscript. CAW supported FR in performing the experiments and analyzing the data. ALS initiated, designed, and coordinated the study and finalized the manuscript. All authors read and approved the final manuscript.

\section{Competing interests}

The authors declare that they have no competing interests.

Received: 20 February 2012 Accepted: 5 April 2012

Published: 5 April 2012

\section{References}

1. Tagliaferri F, Compagnone C, Korsic M, Servadei F, Kraus J: A systematic review of brain injury epidemiology in Europe. Acta Neurochir (Wien) 2006, 148:255-268

2. Maas Al, Stocchetti N, Bullock R: Moderate and severe traumatic brain injury in adults. Lancet Neurol 2008, 7:728-741.

3. Gaetz M: The neurophysiology of brain injury. Clin Neurophysio/ 2004, 115:4-18.

4. Masel BE, DeWitt DS: Traumatic brain injury: a disease process, not an event. J Neurotrauma 2010, 27:1529-1540.

5. Hayes RL, Galinat BJ, Kulkarne P, Becker DP: Effects of naloxone on systemic and cerebral responses to experimental concussive brain injury in cats. J Neurosurg 1983, 58:720-728.

6. Lyeth BG, Dixon CE, Hamm RJ, Jenkins LW, Young HF, Stonnington HH, Hayes RL: Effects of anticholinergic treatment on transient behavioral suppression and physiological responses following concussive brain injury to the rat. Brain Res 1988, 448:88-97.

7. Dixon CE, Clifton GL, Lighthall JW, Yaghmai AA, Hayes RL: A controlled cortical impact model of traumatic brain injury in the rat. $J$ Neurosci Methods 1991, 39:253-262.

8. Klatzo I, Piraux A, Laskowski EJ: The relationship between edema, bloodbrain-barrier and tissue elements in a local brain injury. $J$ Neuropathol Exp Neurol 1958, 17:548-564.

9. Sauerbeck A, Gao J, Readnower R, Liu M, Pauly JR, Bing G, Sullivan PG: Pioglitazone attenuates mitochondrial dysfunction, cognitive impairment, cortical tissue loss, and inflammation following traumatic brain injury. Exp Neurol 2011, 227:128-135.

10. Cederberg D, Siesjö P: What has inflammation to do with traumatic brain injury? Childs Nerv Syst 2010, 26:221-226.

11. Raslan F, Schwarz T, Meuth SG, Austinat M, Bader M, Renne T, Roosen K, Stoll G, Sirén AL, Kleinschnitz C: Inhibition of bradykinin receptor B1 protects mice from focal brain injury by reducing blood-brain barrier leakage and inflammation. J Cereb Blood Flow Metab 2010, 30:1477-1486.

12. Sirén AL, Radyushkin K, Boretius $S$, Kammer D, Riechers CC, Natt O, Sargin D, Watanabe T, Sperling S, Michaelis T, et al: Global brain atrophy after unilateral parietal lesion and its prevention by erythropoietin. Brain 2006, 129:480-489

13. Sargin D, Hassouna I, Sperling S, Sirén AL, Ehrenreich H: Uncoupling of neurodegeneration and gliosis in a murine model of juvenile cortical lesion. Glia 2009, 57:693-702.

14. Mendelow AD, Teasdale GM: Pathophysiology of head injuries. $\mathrm{Br} J$ Surg 1983, 70:641-650.

15. Wolman M, Klatzo I, Chui E, Wilmes F, Nishimoto K, Fujiwara K, Spatz M: Evaluation of the dye-protein tracers in pathophysiology of the bloodbrain barrier. Acta Neuropathol 1981, 54:55-61.

16. Swanson RA, Morton MT, Tsao-Wu G, Savalos RA, Davidson C, Sharp FR: A semiautomated method for measuring brain infarct volume. J Cereb Blood Flow Metab 1990, 10:290-293.

doi:10.1186/2040-7378-4-6

Cite this article as: Raslan et al:: Focal brain trauma in the cryogenic lesion model in mice. Experimental \& Translational Stroke Medicine 2012 $4: 6$.

\section{Submit your next manuscript to BioMed Central and take full advantage of:}

- Convenient online submission

- Thorough peer review

- No space constraints or color figure charges

- Immediate publication on acceptance

- Inclusion in PubMed, CAS, Scopus and Google Scholar

- Research which is freely available for redistribution 